\title{
Deep Loving - The Friend of Deep Learning
}

\section{By Satish Gajawada \& Hassan M. H. Mustafa Indian Institute of Technology Roorkee}

Abstract- Artificial Intelligence and Deep Learning are good fields of research. Recently, the brother of Artificial Intelligence titled "Artificial Satisfaction" was introduced in literature [10]. In this article, we coin the term "Deep Loving". After the publication of this article, "Deep Loving" will be considered as the friend of Deep Learning. Proposing a new field is different from proposing a new algorithm. In this paper, we strongly focus on defining and introducing "Deep Loving Field" to Research Scientists across the globe. The future of the "Deep Loving" field is predicted by showing few future opportunities in this new field. The definition of Deep Learning is shown followed by a literature review of the "Deep Loving" field. The World's First Deep Loving Algorithm (WFDLA) is designed and implemented in this work by adding Deep Loving concepts to Particle Swarm Optimization Algorithm. Results obtained by WFDLA are compared with the PSO algorithm.

Keywords: deep learning, deep loving, artificial intelligence, artificial satisfaction, artificial mothers, swarm intelligence, artificial mother optimization, artificial human optimization, artificial soul optimization, artificial god optimization.

Strictly as per the compliance and regulations of:

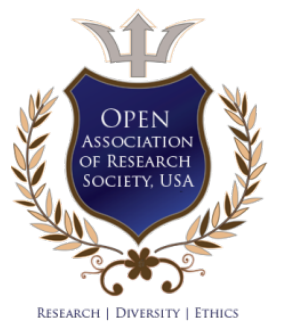

(c) 2020. Satish Gajawada \& Hassan M. H. Mustafa. This is a research/review paper, distributed under the terms of the Creative Commons Attribution-Noncommercial 3.0 Unported License http://creativecommons.org/licenses/by-nc/ 3.0/), permitting all noncommercial use, distribution, and reproduction in any medium, provided the original work is properly cited. 


\title{
Deep Loving - The Friend of Deep Learning
}

\author{
Satish Gajawada ${ }^{\alpha}$ \& Hassan M. H. Mustafa ${ }^{\sigma}$
}

Abstract- Artificial Intelligence and Deep Learning are good fields of research. Recently, the brother of Artificial Intelligence titled "Artificial Satisfaction" was introduced in literature [10]. In this article, we coin the term "Deep Loving". After the publication of this article, "Deep Loving" will be considered as the friend of Deep Learning. Proposing a new field is different from proposing a new algorithm. In this paper, we strongly focus on defining and introducing "Deep Loving Field" to Research Scientists across the globe. The future of the "Deep Loving" field is predicted by showing few future opportunities in this new field. The definition of Deep Learning is shown followed by a literature review of the "Deep Loving" field. The World's First Deep Loving Algorithm (WFDLA) is designed and implemented in this work by adding Deep Loving concepts to Particle Swarm Optimization Algorithm. Results obtained by WFDLA are compared with the PSO algorithm.

Keywords: deep learning, deep loving, artificial intelligence, artificial satisfaction, artificial mothers, swarm intelligence, artificial mother optimization, artificial human optimization, artificial soul optimization, artificial god optimization.

Contribution of Authors:

1. Direct Contribution: Satish Gajawada and Hassan M. H. Mustafa contributed directly, completely, and equally to this article.

\section{Definition of Deep Loving Field}

ust like Mothers in real-world solve real problems, Artificial Mothers (in Deep Loving Field) move in the search space for solving optimization problems. In Deep Loving, we imitate mothers in the real space. In the Artificial Human Optimization field [6-7], Artificial Soul Optimization field [8], and Artificial God Optimization field [9], the basic entities in search space are Artificial Humans, Artificial Souls, and Artificial Gods respectively. Similarly, the basic entities in the Deep Loving Field are Artificial Mothers. Whenever we think of the term "Mother," the Deep Love that each mother shows towards their family, children, etc. comes to mind. Hence the name "Deep Loving Field" is given to the field when Artificial Mothers in search space are imitating Mothers in real-world to solve optimization problems. Instead of naming the field as "Artificial Mother Optimization," a better name "Deep Loving" is chosen by us.

Author a: Indian Institute of Technology Roorkee, Independent Inventor and Scientist, The Creator of Artificial Satisfaction Field, Inventor of Artificial Soul Optimization and Artificial God Optimization Fields, Founder and Father of Artificial Human Optimization Field, Inventor of Deep Loving Field. e-mail: satish.gajawada.iit@gmail.com

Author p: Banha University, Egypt.
II. Infinite OpPortunities IN THE NEW Deep Loving Field

There are INFINITE OPPORTUNITIES for Artificial Intelligence field Research Scientists in Deep Loving Field. Some of them are shown below:

1. International Conference on Deep Loving (ICDL 2020)

2. IEEE TRANSACTIONS on Deep Loving (IEEE TDL 2025)

3. International Workshop on Deep Loving, Harvard University, 2050

4. B.Tech Thesis on Deep Loving, IIT Roorkee, the Year 2075

5. IBM Deep Loving Research Labs, IBM Italy

6. Applied Deep Loving - A New Course

7. Advanced Deep Loving Course, IIT Mumbai

8. M.Tech in Deep Loving Field

9. International Institute of Deep Loving, Greece

10. Ph.D. Thesis on Deep Loving, Stanford University

11. Invited Talk on Deep Loving at Google R\&D Conference, USA

12. Foundation of Deep Loving, Germany

13. International Association of Deep Loving, China

14. Deep Loving team at Microsoft Research and Development

15. YouTube videos on Deep Loving by Samsung R\&D Team

16. Springer Journals on Deep Loving Field

17. Elsevier Book on Deep Loving Field

18. A Course by Deep Loving Experts on Coursera

19. Presentation on Deep Loving Field at Technical Festivals in Singapore Colleges

20. IBMSUR Award for Deep Loving Field Professor at IIT Hyderabad

21. To become a Scientist in Deep Loving Field.

\section{DeEP LEARNING}

According to Wikipedia, the definition of Deep Learning is shown below in double-quotes as it is:

"Deep Learning is part of a broader family of machine learning methods based on Artificial Neural Networks with representation learning. Deep Learning architectures such as deep neural networks, Deep belief networks, recurrent neural networks, and convolutional neural networks have been applied to many fields including computer vision, machine vision, etc" [1].

Hence from the definition, it is clear that Deep Learning is related to Brain-Inspired Computing. 


\section{Literature ReView}

There are many Deep Learning papers published in the literature. But there is not even a single paper which is based on Deep Loving. The World's First Deep Loving method is created in this article. For the sake of completeness, references [2] to [5] show Deep Learning articles. You can easily find references for Deep Learning on websites like deeplearning.net. We just showed four references for Deep Learning for completeness.

\section{World's first DeEp LOVING Algorithm (WFDlA)}

Figure 1 shows the World's First Deep Loving Algorithm (WFDLA). This section explains WFDLA. All
Artificial Mothers are initialized, and the iteration count is set to zero in the beginning. Lines 2-5 find local best, global best, local worst, and global worst of all Artificial Mothers. If Artificial Mother is affected by coronavirus, then there are two possibilities. Either Artificial Mother receives help from others or not. If Artificial Mother is affected by a coronavirus and receives help from others, then she can move in search space and updates Velocity and Position. If Artificial Mother is affected by a coronavirus and doesn't receive help from others, then she is halted and cannot move in search space. Hence, Velocity and Position are not updated. If Artificial Mother is not affected by coronavirus, then she can move in search space and updates Velocity and Position. Figure 1 is shown below:

\begin{tabular}{|c|c|}
\hline 1) & Initialize all Artificial Mothers. Set Iteration Counter to 0. \\
\hline 2) & Find local best of all Artificial Mothers \\
\hline 3) & Find global best of all Artificial Mothers \\
\hline 4) & Find local worst of all Artificial Mothers \\
\hline 5) & Find global worst of all Artificial Mothers \\
\hline 6) & for each Artificial Mother do \\
\hline 7) & if (Random_Number_Generated $<$ CoronavirusProbability) then \\
\hline 8) & if ( Random_Number_Generated < HelpProbability) then \\
\hline 9) & Update Velocity of Artificial Mother \\
\hline 10) & Update Position of Artificial Mother \\
\hline 11) & else \\
\hline 12) & // Mothers affected by coronavirus without help does nothing \\
\hline 13) & end if \\
\hline 14) & else \\
\hline 15) & Update Velocity of Artificial Mother \\
\hline 16) & Update Position of Artificial Mother \\
\hline 17) & end if \\
\hline 18) & end for \\
\hline 19) & Update Iteration Counter \\
\hline 20) & if (termination_condition_reached is not true) then \\
\hline 21) & go to line number 2 \\
\hline 22) & end if \\
\hline
\end{tabular}

Figure 1: World's First Deep Loving Algorithm (WFDLA)

\section{Results}

The ASA algorithm in [10], and WFDLA designed in this paper are MATHEMATICALLY equal. In [10] it was shown that both ASA and PSO algorithms performed well on all benchmark functions. Hence due to MATHEMATICAL EQUALITY, both WFDLA and PSO performed well on all benchmark functions.

\section{Vil. Conclusions}

A new field titled "Deep Loving" is invented in this work. A new algorithm titled "World's First Deep
Loving Algorithm (WFDLA) is designed, and results show that both PSO and WFDLA methods performed well on all benchmark functions. There are INFINITE OPPORTUNITIES in Deep Loving Field. Some interesting opportunities in Deep Loving Field are shown for Deep Learning and Artificial Intelligence Research Scientists and Students. As our focus in this paper is very strong on defining and introducing Deep Loving Field, we just added Deep Loving concepts to the PSO algorithm and created WFDLA for the sake of simplicity. We request Deep Learning and Artificial Intelligence field Experts to invent new Deep Loving algorithms from 
scratch rather than modifying existing algorithms like PSO.

\section{ACKNOWLEDGMENTS}

Thanks to Very Excellent Editorial Team of "Global Journal of Computer Science and Technology (GJCST)" and reviewers for accepting our innovative invention titled "Deep Loving." Thanks to everyone (and everything) who directly or indirectly helped us to reach the stage where we are now today.

\section{References Références Referencias}

1. https://en.m.wikipedia.org/wiki/Deep_learning

2. Training very deep networks (2015), R. Srivastava et al.

3. Deep neural networks are easily fooled: High confidence predictions for unrecognisable images (2015), A. Nguyen et al.

4. How transferable are features in deep neural networks? (2014), J. Yosinski et al.

5. CNN features off-the-Shelf: An astounding baseline for recognition (2014), A. Razavian et al.

6. Satish Gajawada, Hassan Mustafa. Novel Artificial Human Optimization Field Algorithms - The Beginning. arXiv: 1903.12011 [cs.NE].

7. Satish Gajawada, Hassan Mustafa. Ten Artificial Human Optimization Algorithms. Transactions on Machine Learning and Artificial Intelligence, 7(3), 01 16, 2019.

8. Satish Gajawada, Hassan Mustafa. Artificial Soul Optimization - An Invention. Transactions on Machine Learning and Artificial Intelligence, 7(5), 3644, 2019.

9. Satish Gajawada, Hassan M. H. Mustafa. Artificial God Optimization - A Creation. Computer and Information Science. Vol. 13, No. 1 (2020).

10. Satish Gajawada, Hassan M. H. Mustafa. Artificial Satisfaction - The Brother of Artificial Intelligence. Global Journal of Computer Science and Technology, [S.I.], June 2020. 